\title{
Factors related to anxiety before surgery in children in urological operating rooms
}

\author{
Erlis Kurniasari, ${ }^{1}$ Nur Agustini ${ }^{2}$ \\ IFaculty of Nursing; 'Department of Pediatric Nursing, Faculty of Nursing, Universitas Indonesia, Depok, Indonesia
}

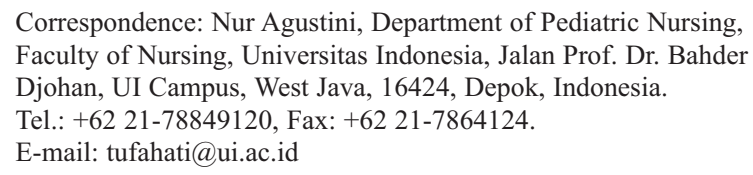

E-mail: tufahati@ui.ac.id

Key words: Adolescent; preoperative anxiety; school-age children.

Acknowledgments: We would like to show our gratitude to Mr. Agus Setiawan, S.Kp., MN., DN., as Dean of the Faculty of Nursing, University of Indonesia. We are also grateful to Dr. dr. Irfan Wahyudi Sp.U(K), as the Head of the Urology Department who has granted permission to study and research at RSUPN Dr. Cipto

Mangunkusumo. Indeed, we express our thanks to Direktorat Riset dan Pengembangan Universitas Indonesia as the agency that funds this research to be published.

Contributions: EK and NA conceived the idea and plan of research, contributed to the design and implementation of the research, and also verified the analytical method. EKwrote the manuscript under NA's advice and suggestion. All authors discussed the results and reviewed the final manuscript.

Conflict of interest: The authors have no conflict of interest.

Funding: This study was supported by Hibah PUTI Saintekes 2020 funded by DirRisBang Universitas Indonesia No. NKB-

4603/UN2.RST/HKP.05.00/2020.

Conference presentation: This final manuscript has been presented at $7^{\text {th }}$ Virtual Biennial International Nursing Conference, Faculty of Nursing, Universitas Indonesia on September 24th October 30th, November $16^{\text {th }} 2020$.

Availability of data and materials: All data generated or analyzed during this study are included in this published article.

Ethics approval and consent to participate: The Ethics Committee of Faculty of Nursing approved this study (SK-86/UN2.F12.D1.2.1/ ETIK.2020). The study is conformed with the Helsinki Declaration of 1964, as revised in 2013, concerning human and animal rights. All patients participating in this study signed a written informed consent form for participating in this study.

Consent for publication: Written informed consent was obtained from a legally authorized representative(s) for anonymized patient information to be published in this article.

Received for publication: 10 November 2020.

Accepted for publication: 26 February 2021.

This work is licensed under a Creative Commons Attribution

NonCommercial 4.0 License (CC BY-NC 4.0).

OCopyright: the Author(s), 2021

Licensee PAGEPress, Italy

La Pediatria Medica e Chirurgica 2021; 43(s1):261

doi:10.4081/pmc.2021.261

\begin{abstract}
This study aimed to determine the factors associated with preoperative anxiety in school-age children and adolescents at one of top hospital in the capital city of Indonesia. This study used analytical cross-sectional study. The selection of respondents used proportional stratified random sampling with a total of 86 respondents consisting of 43 school age children and 43 adolescents. Data analysis employed was the Chi-Square and Independent TTest. The results showed that anxiety was being experienced by $54.7 \%$ of respondents. In this study, it was found that there was a significant relationship $(\mathrm{p}<\alpha)$ among children anxiety before surgery and age, family presence, previous operating experience and patient waiting time. Meanwhile, there was no significant relationship between gender and anxiety level before surgery in children. The results of this study can be used as the basis and reference for the hospital in making policies regarding efforts to manage anxiety before surgery in children. Accordingly, nurses could make appropriate nursing care interventions in preoperative patients to overcome preoperative anxiety experienced by schoolage children and adolescents.
\end{abstract}

\section{Introduction}

Anxiety is an emotional condition that has no specific object and is experienced subjectively with a sense of uncertainty, helplessness, isolation and insecurity. ${ }^{1,2}$ Anxiety is the thing most often reported when a child is exposed to a stressful surgery or medical procedure. ${ }^{3}$ Anxiety can also affect the physical and psychological health of children.2,3 An observational study conducted on children in the United States found more than 5 million children undergo surgery each year and more than $50-70 \%$ of children who undergo surgery experience fear and anxiety before surgery. ${ }^{3-6}$ Based on data obtained in the last ten months, namely January-October, the number of children hospitalized was 1081 and there were 233 children who underwent surgery in the urology operating room. ${ }^{4}$

Facts from the field show that in surgery with local anesthesia, good cooperation with children and the families is needed to help the operation run well. The uncooperative action with children and family can be the cause of the surgery cancellation in the urology operating room. Preoperative anxiety children can manifest their anxiety by crying loudly, rebelling, hitting, even biting the medical staff making it difficult to carry out the procedure and it leads to the surgery cancellation. ${ }^{7}$

Based on a simple interview conducted by the author with several nurses working in the urology operating room, it is shown that $70-80 \%$ pediatric patients indicate moderate anxiety on scheduled surgical procedure. They said they were afraid of anesthesia, post-surgery pain and being injected. The purpose of this 
study was to determine the factors associated with anxiety prior to surgery in school-age children and adolescents in Dr. Cipto Mangunkusumo National Central Public Hospital (RSUPN Dr. Cipto Mangunkusumo) in 2020. This research is expected to be benefits to hospitals, society, science and researchers.

\section{Materials and Methods}

This research is an analytical study with a cross sectional design with a correlation study. Respondents were selected by proportional stratified random sampling method with a total of 86 respondents. Research data collection used a questionnaire instrument. The questionnaire in this study used the Chinese version of the State Anxiety Scale for Children (CSAS-C) anxiety questionnaire, which was modified by increasing the range of assessment score according to the research needs. ${ }^{7-10}$

Data collection using a questionnaire was carried out 10-15 minutes before the patient underwent surgery. Respondents were asked to provide answers or responses to each item of statements raised. The questionnaire had been tested for validity and reliability on 30 patients of school-age children and adolescents who would undergo surgery with the results of the Cronbach's Alpha reliability test of 0.935 ( $\mathrm{r}$ table value of 0.355 ) meaning that the instrument was valid and reliable. This study has received approval from the FIK UI ethics commission and The Ethic Committee of the Faculty of Medicine, Universitas Indonesia.

After the respondent questionnaires were filled and collected, the data processed was carried out by means of edited, coded, scored, tabulated, data entry, and cleaned. After the total score was obtained, the next process was to categorize the respondents based on the variables studied. The process of univariate data analysis in this study describes the frequency distribution of all the variables studied, namely the characteristics of the respondent (age, gender, previous operating experience, family presence and patient waiting time before surgery), independent variables related factors with anxiety and the dependent variable the level of anxiety before surgery.

Bivariate analysis used to determine the relationship between two variables, independent and the dependent variable, which were the factors associated with preoperative surgery a in school-age children and adolescents. The statistical tests used to determine the relationship and to prove the hypothesis of the relationship between the two variables in this study were the Chi-Square and the Independent T-test.

\section{Results}

Based on Table 1, it is indicated that of the 86 school-age children and adolescents who would undergo surgery at RSCM were mostly male $(62.8 \%)$, had previous operating experience $(65.1 \%)$, accompanied by family $(60.5 \%)$, and required to wait before surgery for more than 30 minutes $(51.2 \%)$.

Based on Table 2, it is shown that of the 86 school-age children and adolescents who would undergo surgery experienced moderate anxiety $(54.6 \%)$.

Based on Table 3, of the 86 preoperative school-age children and adolescents, the average age of the respondent was 11.93 years (SD 3.198). The youngest was 7 and the oldest was 18 years old.

Table 1. Description of the characteristics of preoperative respondents at RSCM $(n=86)$.

\begin{tabular}{lcc} 
Variable & Frequency (n) & \\
Gender: & 54 & 62.8 \\
a. Male & 32 & 37.2 \\
b. Female & 30 & 34.9 \\
Experience in Surgery: & 56 & 65.1 \\
a. Never & & 39.5 \\
b. Ever & 34 & 60.5 \\
\hline Family Presence: & 52 & 51.2 \\
a. No (accompanied by other than parents) & & 48.8 \\
b. Yes (accompanied by parents) & 44 & \\
The length of time the Patient waits before surgery: & 42 & \\
a. more than 30 minutes & & \\
b. less than 30 minutes &
\end{tabular}

Table 2. Frequency distribution of preoperative anxiety levels in school-age children and adolescents in RSCM ( $\mathbf{n = 8 6}$ )

\begin{tabular}{lcc} 
Anxiety level & Frequency(n) & Precentage(\%) \\
Mild & 25 & 29.1 \\
Moderate & 47 & 54.6 \\
\hline Severe & 14 & 16.3 \\
Total & 86 & 100.0 \\
\hline
\end{tabular}

Table 3. Frequency distribution of preoperative respondents based on Age at RSCM ( $n=86)$.

\begin{tabular}{lcccc} 
Variable & Mean & SD & Min-Max & $95 \% \mathrm{CI}$ \\
Age (Years) & 11.93 & 3.198 & $7-18$ & $4.678-7.373$ \\
\hline
\end{tabular}


From the statistical test, it can be concluded that there was a relationship between age and anxiety before surgery in children in the urological operating rooms (Table 4).

From the results of the Chi Square test, the relationship between gender and anxiety levels in preoperative children at RSCM showed a p-value of 0.113 ( $p$ value $>0.05$ ) using $5 \%$ alpha (0.05) (Table 5). This can be concluded that Ho was accepted, which means that there was no relationship between gender and anxiety levels before surgery in school-age children and adolescents. The relationship between previous operation experience and anxiety level before surgery indicated a p-value of 0.02 $(<$ alpha $=0.05)$ using $5 \%$ alpha $(0.05)$. This can be concluded that Ho was rejected, which means that there was a relationship between previous operating experience and anxiety levels before surgery in school-age children and teenagers.

The relationship between family attendance and anxiety levels before surgery in children indicated a p-value of $0.00(<$ alpha $=0.05)$ using $5 \%$ alpha (0.05). This can be concluded that Ho was rejected meaning that there was a relationship between family attendance and anxiety levels before surgery in school-age children and teenager. The relationship between the explicitness of surgery information with preoperative anxiety levels in children shown that respondents with a complete information about the operation experienced mild anxiety as much as $29.1 \%$, moderate anxiety $54.7 \%$ and severe anxiety $16.3 \%$. The relationship of patient waiting time prior to surgery with anxiety levels in preoperative children showed a p-value of $0.022(<$ alpha $=0.05)$ using $5 \%$ alpha $(0.05)$. This can be concluded that Ho was rejected, which means that there was a relationship between waiting time and the level of anxiety prior to surgery in school-age children and teenager.

\section{Discussion}

The results showed that of 86 respondents $54.6 \%$ of respondents were preoperative children with moderate anxiety. Most of them experienced moderate anxiety in a total of 47 (54.6\%); meanwhile, those who experienced mild anxiety were in a total of 25 $(29.1 \%)$, and the number for severe anxiety sufferers was 14 $(16.3 \%)$. Furthermore, the mean age of respondents with mild anxiety level was 15.24 years $\mathrm{SD}=1.422$; this is the lowest compared to those with moderate anxiety which is 10.98 years $\mathrm{SD}=2.566$, and those with severe anxiety which is 9.21 years $\mathrm{SD}=2.751$. Also, most of male respondents experienced moderate anxiety in a total of $63 \%$. Likewise, most female respondents experienced moderate and mild anxiety in a number of $40.6 \%$. The sex of the respondents involved in this study was prevalently male than female. For female, it is only a small proportion in number representing characteristics based on gender. This study was conducted in the urology operating room and the cases occurred mostly in male patients, such as those with hypospadias.

Respondents who have never had surgery before experienced different levels of anxiety, such as moderate anxiety as much as $53.3 \%$, mild anxiety by $16.7 \%$ and severe anxiety by $30 \%$. Respondents who had previously undergone surgery experienced moderate anxiety more in a total of $55.4 \%$ and severe anxiety in. a number of $8.9 \%$. In this study, the experience of surgery in children can occur due to congenital diseases that require surgery to be carried out in stages and also because of reconstructions or surgeries that require insertion of tools (implants) and removal of the tools within a certain period of time. Regarding the relation between family presence and anxiety levels in preoperative children, it is indicated that out of 52 children with family presence, experienced moderate anxiety in a total of $37(71.2 \%)$, and severe anxiety in a number of $3(5.8 \%)$; meanwhile, those without family presences had moderate anxiety in a total of $10(29.4 \%)$ and severe anxiety in a number of $11(32.4 \%)$.

Regarding the patient's waiting time before surgery and the level of anxiety in preoperative children, it is shown that respondents who underwent on time surgery experienced moderate anxiety namely $19(45.2 \%)$ and $5(11.9 \%)$ experienced severe anxiety. Meanwhile, 28 respondents $(63.6 \%)$ experienced moderate anxiety and $9(20.5 \%)$ experienced severe anxiety. This state of anxiety

Table 4. The relationship between age and anxiety levels in preoperative school-age children and adolescents in RSCM ( $\mathrm{n}=86$ )

\begin{tabular}{lcccccccccc} 
Variable & \multicolumn{3}{c}{ Mild Anxiety } & \multicolumn{4}{c}{ Moderate Anxiety } & \multicolumn{5}{c}{ Severe Anxiety } \\
& Mean & SD & SE Mean & Mean & SD & SE Mean & Mean & SD & SE Mean \\
Age (Years) & 15.24 & 1.422 & 0.284 & 10.98 & 2.566 & 0.374 & 9.21 & 2.751 & 0.735 & 0 \\
\hline
\end{tabular}

Table 5. Description of the relationship variables of preoperative respondents at RSCM (n=86).

\begin{tabular}{|c|c|c|c|c|c|c|c|}
\hline \multirow[t]{2}{*}{ Variable } & \multicolumn{2}{|c|}{$\begin{array}{l}\text { Mild Anxiety } \\
\qquad(\mathrm{n}=25)\end{array}$} & \multicolumn{2}{|c|}{$\begin{array}{l}\text { Moderate Anxiety } \\
\qquad(\mathrm{n}=47)\end{array}$} & \multicolumn{2}{|c|}{$\begin{array}{l}\text { Severe Anxiety } \\
\quad(n=14)\end{array}$} & \multirow[t]{2}{*}{ P Value* } \\
\hline & n & $\%$ & $\mathbf{N}$ & $\%$ & n & $\%$ & \\
\hline $\begin{array}{l}\text { Gender } \\
\text { a. Male } \\
\text { b. Female }\end{array}$ & $\begin{array}{l}12 \\
13\end{array}$ & $\begin{array}{l}22.2 \\
40.6\end{array}$ & $\begin{array}{l}34 \\
13\end{array}$ & $\begin{array}{c}63 \\
40.6\end{array}$ & $\begin{array}{l}8 \\
6\end{array}$ & $\begin{array}{l}14.8 \\
18.8\end{array}$ & 0.113 \\
\hline $\begin{array}{l}\text { Experience in Surgery } \\
\text { a. Never } \\
\text { b. Ever }\end{array}$ & $\begin{array}{c}5 \\
20 \\
\end{array}$ & $\begin{array}{l}16.7 \\
35.7\end{array}$ & $\begin{array}{l}16 \\
31\end{array}$ & $\begin{array}{l}53.3 \\
55.4 \\
\end{array}$ & $\begin{array}{l}9 \\
5\end{array}$ & $\begin{array}{l}30 \\
8.9\end{array}$ & 0.02 \\
\hline $\begin{array}{l}\text { Family Presence } \\
\text { a. No (accompanied by other than parents) } \\
\text { b. Yes (accompanied by parents) }\end{array}$ & $\begin{array}{l}13 \\
12\end{array}$ & $\begin{array}{c}38.2 \\
37\end{array}$ & $\begin{array}{l}10 \\
37\end{array}$ & $\begin{array}{l}29.4 \\
71.2\end{array}$ & $\begin{array}{c}11 \\
3\end{array}$ & $\begin{array}{c}32.4 \\
5.8\end{array}$ & 0 \\
\hline $\begin{array}{l}\text { Patient waiting time before surgery } \\
\text { a. Late start of surgery, if the patient's waiting time }>30 \text { minutes } \\
\text { b. Start surgery on time, if patient's waiting time } \leq 30 \text { minutes }\end{array}$ & $\begin{array}{c}7 \\
18\end{array}$ & $\begin{array}{l}15.9 \\
42.9\end{array}$ & $\begin{array}{l}28 \\
19\end{array}$ & $\begin{array}{l}63.6 \\
45.2\end{array}$ & $\begin{array}{l}9 \\
5\end{array}$ & $\begin{array}{l}20.5 \\
11.9\end{array}$ & 0.022 \\
\hline
\end{tabular}


was a psychological problem associated with the occurrence of negative effects on children during preoperative and this was not expected by the patient. ${ }^{8}$ As argued by Aytekin and Kucukoglu, there are several reasons for patients who enter the hospital and will undergo surgery experiencing anxiety before surgery, such as being away from parents, losing control over themselves, being unfamiliar with operating room environment, being scared of anesthesia and surgical procedures, having no experience previous operations, and having the need for social support from the family. $5,7,12,13$ This was in line with research conducted by Perry, Hooper, and Masiongale which states that there are more than 5 million children who experience surgery every year, and more than $50-70 \%$ of children who undergo surgery experience fear and anxiety before surgery. ${ }^{6}$

Most of preoperative children experienced moderate anxiety levels in a total of $47(54.6 \%)$, with mild anxiety levels in a number of $25(29.1 \%)$, and $14(16.3 \%)$ with severe anxiety. This is in line with the research of Ahmed et al. which stated that more than $65 \%$ of children who experience anxiety are related to anxiety in the preoperative period. Ahmed et al. also explained that anxiety before surgery occurred due to various factors, namely child factors (age, temperament, previous operating experience, quality of parent-child relationships, children with delayed growth and development), parental factors and operating room environmental factors (stimulus, anesthesia techniques and medical staff). ${ }^{16}$

This is in line with research by Lita Nurlita explaining that there was a strong relationship between age and anxiety scores, but there was a negative correlation direction $(-0.198)$ which the older the patient, the more anxiety score decreases. 10 This is reinforced by the theory of Stuart stating that someone who was younger was more prone to experiencing anxiety disorders than someone who was older. ${ }^{8}$ Ahmed et al. also explained in their research on Preoperative Anxiety in Children Risk Factors and NonPharmacological Management that one of the factors in children experiencing anxiety before surgery was previous operating experiences. Children with bad operating experiences would remember until they grew up, and it is stated that $67 \%$ of children developed negative postoperative behaviors. 16

The anxiety experienced by parents during medical procedures and children's hospitalization would affect the ability of parents to respond to children's emotional needs and to help children in using effective coping strategies. ${ }^{9}$ The one that could calm the child at the initial procedure of anesthesia was the parent. It is stated that stress could be transferred from the parent to the child; so when the parent was not anxious the child was expected to calm down too. ${ }^{13,14}$ This is in line with the opinion of Ahmed et al. regarding Preoperative Anxiety in Children Risk Factors and NonPharmacological Management. Ahmed et al. explained that an increase in the level of anxiety in children is related to an increase in the number of people or health workers in the anesthesia induction room and the longer the waiting time for children in the preparation room for surgery, the more the child's anxiety would increase. 6

\section{Nursing implication}

The service institution (hospital) as the policy holder is expected to pay more attention to the age factor of the children being treated and to make therapeutic approaches and communications according to age levels. The service institution (hospital) is also advised to facilitate the improvement of the human resource capacity of nursing through dissemination of research results, seminars, training and other formal education. Nurses who work in the children's room are expected to be able to help families overcome the anxiety faced by children and also parents by providing emotional and psychological support in generalist and specialist therapy related to handling anxiety in children and parents.

\section{Conclusions}

The characteristics of the respondents in this study were 11.93 years old with the majority of male patients. Most respondents have had previous surgery and mostly with family presence before surgery. All respondents got complete information about surgery. Some of them underwent late surgery. Most preoperative respondents in urology surgery rooms experienced moderate anxiety. There was a significant relationship among the age of respondents, the experience of previous surgery, family attendance (parents), preoperative patient waiting time and the level of anxiety in preoperative school-age children and adolescents. There is no significant relationship between gender and the level of anxiety in preoperative school-age children and adolescents.

\section{References}

1. Hockenberry M, Wilson D, Rodgers C. Wong's essentials of pediatric nursing. 10th ed. Canada: Elsevier Pte Ltd; 2017.

2. Baghele A, Dave N, Dias R, Shah H. Effect of preoperative education on anxiety in children undergoing day-care surgery. Indian J Anaesth 2019;63:565-70.

3. Fortier MA, Kain ZN. Treating perioperative anxiety and pain in children: a tailored and innovative approach. Paediatr Anaesth 2015;25:27-35.

4. Vaezzadeh N, Douki ZE, Hadipour A, et al. The effect of performing preoperative preparation program on school age children's anxiety. Iran J Pediatr 2011;21:461-6.

5. Adams HA. A perioperative education program for pediatric patients and their parents. AORN J 2019;93:472-81.

6. Perry JN, Hooper VD, Masiongale J. Reduction of preoperative anxiety in pediatric surgery patients using age-appropriate teaching interventions. J Perianesth Nurs 2012;27:69-81.

7. Matthyssens LE, Vanhulle A, Seldenslach L, et al. A pilot study of the effectiveness of a serious game CliniPup $(\AA$ on perioperative anxiety and pain in children. J Pediatr Surg 2020;55:304-11.

8. Dr. Cipto Mangunkusumo National Central Public Hospital (RSUPN Dr. Cipto Mangunkusumo). Internal Data for RSCM Operation Room Urology Unit. Jakarta: Rumah Sakit Umum Pusat Nasional Dr. Cipto Mangunkusumo; 2019.

9. Meletti DP, Meletti JFA, Camargo RPS, et al. Psychological preparation reduces preoperative anxiety in children. Randomized and double-blind trial. J Pediatr (Rio J) 2019;95:545-51.

10. Nurlita L. Pengaruh buku cerita bergambar terhadap kecemasan sebelum operasi pada anak usia sekolah di RSUP Dr. Hasan Sadikin Bandung. Thesis. Depok: Universitas Indonesia; 2015.

11. Li HCW, Lopez V. Development and validation of a short form of the Chinese version of the state anxiety scale for children. Int J Nurs Stud 2007;44:566-73.

12. de Moura LA, Dias IMG, Pereira LV. Prevalence and factors associated with preoperative anxiety in children aged 5-12 years. J Pediatr Nurs 2016;24:e2708.

13. Aytekin A, Doru Ö, Kucukoglu S. The effects of distraction on preoperative anxiety level in children. J Perianesth Nurs 2016;31:56-62.

14. Bartik K, Toruner EK. Effectiveness of a preoperative prepara- 
tion program on children's emotional states and parental anxiety. J Perianesth Nurs 2018;33:972-80.

15. Nigussie S, Belachew T, Wolancho W. Predictors of preoperative anxiety among surgical patients in Jimma University Specialized Teaching Hospital, South Western Ethiopia. BMC Surg 2014;14:67.

16. Ahmed MI, Farrell MA, Parrish K, Karla A. Preoperative anxiety in children risk factors and non-pharmacological management. Middle East J Anaesthesiol 2011;21:153-64.

17. Stuart GW. Principles and practice of psychiatric nursing. 10th ed. St. Louis, MO: Mosby; 2013.
18. DeMaso DR, Snell C. Promoting coping in children facing pediatric surgery. Semin Pediatr Surg 2013;22:134-8.

19. Sadeghi A, Tabari AK, Mahdavi A, et al. Impact of parental presence during induction of anesthesia on anxiety level among pediatric patients and their parents: a randomized clinical trial. J Neupsychiatr Dis Treat 2017;12:3237-41.

20. Ozdogan HK, Cetinalp S, Kuran G, et al. The effects of maternal presence during anesthesia induction on salivary cortisol levels in children undergoing tonsillectomy and/or adenoidectomy. J Clin Anesth 2017;39:64-6. 